\title{
Tethered capsule endomicroscopy
}

\section{By Tracey Baas, Senior Editor}

Massachusetts General Hospital researchers have created a new kind of endoscopy device that resembles a large plastic vitamin capsule on a tether and can generate 3D microstructural images of the upper GI tract. ${ }^{1}$ As proof of concept, the team used the device to image Barrett's esophagus in patients. The technology is licensed to NinePoint Medical Inc.

Recurrent acid reflux, which usually presents as heartburn, can lead to cells in the epithelium of the lower esophagus being replaced with GI-like cells and abnormal microstructure. This condition is diagnosed as Barrett's esophagus and can progress from dysplasia to esophageal cancer. $^{2}$

To diagnose Barrett's esophagus, the current standard is a method called endoscopic biopsy, during which doctors sedate a patient, insert an endoscope down the esophagus to look for abnormal tissue and then

\section{"The technique also} could be used to assess inflammatory diseases of the esophagus, such as squamous cell cancer and its precursors, and assess changes in the small bowel related to celiac disease."

- Charles Carignan, NinePoint Medical Inc. cut off a small piece of the organ for laboratory analysis-this leaves the patient with a sore throat for the next couple of days.

An alternative method is to use a capsule endoscope, which is a clear plastic pill that contains a video camera. The pill is swallowed by the patient and takes images of the GI tract.

There is one capsule endoscope on the market to image the esophagus-the PillCam ESO from Given Imaging Ltd. The product houses two cameras-one at each end-that are capable of acquiring 14 images per second. ${ }^{3}$

Unlike a full endoscope procedure, however, the video imaging can only provide information about superficial mucosal structures and not microscopic features below the tissue surface. Thus, histological diagnosis of Barrett's esophagus is not possible.

Instead, PillCam ESO gives a diagnosis of endoscopic suspicion of esophageal metaplasia. ${ }^{4,5}$ Patients who test positive for that typically undergo an actual endoscope procedure to identify lesions and collect biopsies to evaluate for dysplasia.

The MGH team, led by Guillermo Tearney, wanted to overcome the resolution problems intrinsic to video imaging. To do so, the group engineered a capsule that captures snapshots with optical frequency domain imaging (OFDI), a technique that is similar to ultrasound. The pill performs more like a microscope than a video camera.

The snapshots can then be put together-computationally stacking the data collected from the OFDI-to reconstruct a 3D image of the esophagus and provide enough detail and depth to allow the diagnosis of abnormal growth patterns in esophageal tissue.

Tearney is a professor of pathology at Harvard Medical School, MGH research scholar and associate director of the Wellman Center for Photomedicine at MGH.

The team's first step was slowing down the transit of the capsule in the esophagus to allow it to collect enough snapshots to produce a $3 \mathrm{D}$ representation of the esophagus. The group placed the capsule on a tether, which enabled the operator to move the capsule up and down, thus allowing for multiple passes in the esophagus.

As proof of concept, the tethered capsule collected images in six individuals with Barrett's esophagus and seven healthy individuals. The image collection time took about six minutes, and after the procedure the capsule could be recovered, disinfected and reused.

The technology showed clear evidence of Barrett's in those with the disease, whereas those without Barrett's had a normal scan.

"This is not the first time either a tethered capsule or OFDI has been used to attempt to diagnose Barrett's, but using the two techniques together, this is the first time accurate diagnosis can be made using a fairly noninvasive technique," said Tearney. ${ }^{6-10}$

Results were published in Nature Medicine.

\section{Getting to the NinePoint}

NinePoint plans to optimize the tethered capsule technology and run imaging and diagnostic trials in larger sets of patients.

Marc Schurr thinks that "the imaging contrast seems appropriate to be used for diagnostics, but clinical trials with an appropriate number of cases will be needed to establish specificity and sensitivity of the procedure."

Schurr is managing director of novineon Healthcare Technology Partners $\mathbf{G m b H}$ and leader of a consortium of 18 European teams working on the VECTOR (versatile endoscopic capsule for gastrointestinal tumor recognition and therapy) project.

NinePoint thinks that capsule endoscopy, after optimization, could be used throughout the GI tract to obtain information about diseases of the esophagus, stomach and upper small bowel.

"We will be focusing first on the esophagus because it is the easier site to image in the GI tract," said Tearney, who is a consultant to NinePoint.

"The technique also could be used to assess inflammatory diseases of the esophagus, squamous cell cancer and its precursors and changes in the small bowel related to celiac disease," said Charles Carignan, founding president and CEO of NinePoint. "If we were able to create a wireless device that does not require the tether, the device could have additional applicability in the lower small bowel and possibly colon."

"In the near future, we are most interested in improving the capsule by adding controlled locomotion and video imaging for guidance," he noted.

This would give greater control in GI sites downstream of the esophagus. 


\section{ANALYSIS}

A patent application has been filed by MGH, and NinePoint has licensed the technology.

NinePoint's lead product is a balloon-based optical coherence tomography system that can be used through existing endoscopes to image microstructures of organs such as the esophagus and identify areas for biopsy and treatment. It is the same technology underlying the tethered capsule. This technology, which originated in Tearney's and Brett Bouma's lab, will be commercialized this year.

Bouma is a professor of dermatology and health sciences and technology at HMS and an associate physicist at the Wellman Center for Photomedicine at MGH.

NinePoint also has licensed rights to a volumetric confocal technology from MGH that allows imaging of mucosa at a cellular level. This technology could be developed in a balloon- or capsule-based method to allow characterization of mucosal abnormalities in the body, such as eosinophilic esophagitis.

Baas, T. SciBX 6(6); doi:10.1038/scibx.2013.131

Published online Feb. 14, 2013

\section{REFERENCES}

1. Gora, M.J. et al. Nat. Med.; published online Jan. 13, 2013; doi:10.1038/nm.3052

Contact: Guillermo Tearney, Massachusetts General Hospital and Harvard Medical School, Boston, Mass. e-mail: gtearney@partners.org

2. Reid, B.J. et al. Nat. Rev. Cancer 10, 87-101 (2010)

3. Moglia, A. et al. Nat. Rev. Gastroenterol. Hepatol. 6, 353-362 (2009)

4. Galmiche, J.P. et al. Gut 57, 695-703 (2008)

5. Vakil, N. et al. Am. J. Gastroenterol. 101, 1900-1920 (2006)

6. Evans, J.A. et al. Gastrointest. Endosc. 65, 50-56 (2007)

7. Evans, J.A. et al. Clin. Gastroenterol. Hepatol. 4, 38-43 (2006)

8. Poneros, J.M. et al. Gastroenterology 120, 7-12 (2001)

9. Ramirez, F.C. et al. Gastrointest. Endosc. 68, 25-31 (2008)

10. Gilani, N. et al. Gastrointest. Endosc. 66, 1091-1095 (2007)

COMPANIES AND INSTITUTIONS MENTIONED

Given Imaging Ltd. (NASDAQ:GIVN; Tel Aviv:GIVN), Yoqneam, Israel Harvard Medical School, Boston, Mass.

Massachusetts General Hospital, Boston, Mass.

NinePoint Medical Inc., Cambridge, Mass.

novineon Healthcare Technology Partners GmbH, Tuebingen, Germany 